to all laboratories is nevertheless indisputable and quite independent of the organization-level from which it is viewed. There are six parts to the book, dealing with the new laboratory, laboratory organization and maintenance, accident precautions, special and auxiliary units, purchases and records, and staff problems and human relations. These parts are subdivided and filled with information and advice on design, organization, equipment and documentation. This information and advice is of a kind which is obviously based on a wide experience of practical laboratory management and has rarely been recorded in an accessible form.

Stores organization and fire precautions are particularly well dealt with. The special and auxiliary units include the radioactive materials laboratory, lecture theatre, photographic processes, workshops and library.

Those who occasionally import apparatus or chemicals will welcome the chapter on Customs and Excise procedures. This chapter deals also with applications for industrial methylated spirit, duty-free spirit and permission to use stills. It is admirably concise and informative.

The book is well produced and illustrated. It will be of great value to all whose duties include the provision of the ways and means of scientific endea. vour.

E. I. JoHNSON

\section{Lehrbuch der Organischen Chemie}

13, neubearbeitete und erweiterte Auflage. Von Prof. Paul Karrer. Pp. $x x+1080$. (Stuttgart: Georg Thieme Verlag, 1959.) 60 D.M.

RGANIC chemistry has undergone a great transformation both in extent and depth since Prof. Karrer's classic text-book first appeared in 1927 , and much of this change has come about during the ten years that separate the last English from the new German edition of this work. Prof. Karrer has given recognition to this fact by inviting a group of authorities to revise and enlarge the existing text and to contribute a number of new chapters. The general layout and the major portion of the contents, however, remain unaltered.

While some of the newly written chapters, as, for example, those on conformational analysis, steroids, and amino-acids and polypeptides, are excellent, the shorter sections inserted into the old text are generally not well assimilated so that a consistent presentation fails to emerge. In particular the treatment of reaction mechanisms leaves an unsatisfactory impression. Throughout the book they are presented without formal consistency and the basis for their inclusion or omission is not readily apparent; alternative mechanisms are listed uncritically (Cannizzaro reaction, pinacol rearrangement, aldol condensation) and some are of an unorthodox nature (ester saponification, hemiacetal formation). Two further points of criticism force themselves on the reader's attention. A good deal of up-to-date information has been included, but at times abbreviated to an extent which obscures its significance (chemistry of caryophyllene, biogenetic role of phenol dehydrogenations). On the other hand, there are some surprising omissions (mechanism of halogen and halogen acid addition to olefins, Michael addition, Bredt's rule).

Prof. Karrer's book has for many years occupied a leading place among the text-books of organic chemistry. Its principal virtue still lies in the generous amount of factual information to be found within its covers, but one wonders whether its value as a pedagogic text can be effectively maintained by the method that has been adopted in this latest edition.

K. H. Overton

\section{Radiation : Use and Control in Industrial Appli- cation}

By Charles Wesley Shilling. (Modern Monographs in Industrial Medicine, Vol. 5.) Pp. viii + 223. (New York and London: Grune and Stratton, Inc., 1960.) 6.75 dollars.

N his preface, Dr. Shilling emphasizes that this book is non-technical and is intended for the person who needs only a working knowledge of the subject; in particular "the physician who must handle radiation exposure and injury cases and who must answer questions concerning the mysteries of radiation". In consequence the book has been written with a medical bias, but the author's aims have not been achieved since the treatment of the physical aspects of protection, such as shielding, instrumentation and monitoring techniques, is meagre and rather inadequate.

The first section of the book covers the origin and nature of the radiations and the dose to man due to natural sources, and is followed by sections on the prevention and treatment of radiation injury, the control of radiation and the use of radioisotopes. Although the treatment of each topic is, of necessity, concise, the subject-matter on the medical aspects is sufficient to acquaint the industrial physician with the various problems and to provide a basis for further reading. It should be noted, however, that the control procedures are considered from the United States point of view, and British readers should acquaint themselves with the national legislation and recommendations.

Some of the illustrations appear unnecessarily elementary and there are one or two errors in the text; for example, the maximum permissible concentration of radionuclides in air and water for the exposure of the entire population is given as onetenth of the occupational exposure-level, whereas for individuals the International Commission on Radiological Protection recommends a reduction factor of one hundred. However, these errors are not serious provided the book is used for general reading rather than as a text-book.

B. E. JONES

\section{Commutative Algebra}

Vol. 2. By Prof. Oscar Zariski and Prof. Pierre Samuel. (The University Series in Higher Mathematics.) Pp. $x+414$. (Princeton, N.J.: D. Van Nostrand Company, Inc.; London: D. Van Nostrand Company, Ltd., 1960.) 588. $6 d$.

7 HE first volume of this work was published in 1958. Now that the second volume has appeared it is possible to be much clearer on the motivation behind the subject as a whole. This is buried in the history of algebraic geometry, and the authors have been careful to indicate what parts of geometry have led to the immense algebraic developments of recent years. The book is very carefully written and will be an essential reference, and even a text-book, for the pure mathematician who moves or wishes to move in this field.

There are three long chapters, given to valuation theory, polynomial and power series rings and local algebra. In addition there is an appendix of about eighty pages containing a good deal of previously unpublished material. The contents of the chapter 